\title{
Factors Associated with Linkage to HIV Care Among Oral Self-Tested HIV Positive Adults in Uganda
}

\author{
Mudarshiru Bbuye $\mathbb{D}^{1,2}$, Winters Muttamba $\mathbb{D}^{2}$, Laillah Nassaka ${ }^{3}$, Damalie Nakyomu ${ }^{3}$, Geoffrey Taasi ${ }^{4}$, \\ Sarah Kiguli ${ }^{5}$, Roy William Mayega', Aggrey David Mukose' \\ 'Department of Epidemiology and Biostatistics, School of Public Health-Makerere University, Kampala, Uganda; ${ }^{2}$ Makerere University Lung Institute, \\ Makerere University College of Health Sciences, Kampala, Uganda; ${ }^{3}$ Lira University, Lira, Uganda; ${ }^{4}$ Aids Control Program-Ministry of Health, Kampala, \\ Uganda; ${ }^{5}$ Department of Paediatrics and Child Health, School of Medicine-Makerere University, Kampala, UgAnda
}

Correspondence: Mudarshiru Bbuye, School of Public Health-Makerere University, New Mulago Hospital Complex, P.O. Box 22864, Kampala, Uganda, Tel +256 773082633, Email mudarshirubbuye@gmail.com

Background: HIV oral self-testing (HIVST) was rolled out in Uganda in 2018. However, data reported by public facilities show that less than $60 \%$ of oral self-tested HIV positive adults were linked to HIV care. This study set out to determine the factors associated with linkage to HIV care among adults with positive HIV oral self-test results in Uganda.

Methods: A cross-sectional study was carried out at Nabweru HCIII and Entebbe Hospital in central Uganda. The study reviewed medical records from January 2019 to May 2020 and successfully invited 144 self-tested HIV positive participants for the quantitative interview process. Data on socio-demographics and health-related characteristics were collected. Bivariate and multivariable analysis was used to determine the factors associated with linkage to care.

Results: The proportion of participants linked to HIV care was $69.6 \%(100 / 144)$. The majority of the participants were female (71\%), with a mean age of $29( \pm 8)$ years. Participants within age groups of 31-35 years and 41-60 years, who used directly assisted HIVST, disclosed their HIV status to their sexual partners, are ready to start ART, do not consume alcohol and having a supportive sexual partner were more likely to be linked to HIV care. Single participants, separated/divorced, female, fear unfair treatment after HIV status disclosure and those who fear ART side effects were less likely to be linked to HIV care.

Conclusion: Our study showed that less than $70 \%$ were linked to HIV care. It also shows that HIV status disclosure, readiness to start ART, type of HIVST used, fear of ART side effects, and being divorced/separated negatively associated with linkage to HIV care among self-test HIV positive adults. There is a need for HIV programs to address the above factors to improve linkage to HIV care to realize the national targets towards the UNAIDs 2035 goals.

Keywords: linkage to HIV care, HIV oral self-testing, Uganda

\section{Background}

Sub-Saharan Africa (SSA) has seen a general increase in antiretroviral therapy (ART) access despite HIV/AIDS-related mortality remaining high. ${ }^{1}$ In SSA, only $57 \%$ of the people living with HIV (PLHIV) accessed HIV diagnosis, $66 \%$ started ART in 2018, thus increasing their risk of advanced morbidity and mortality associated with HIV/AIDS. ${ }^{2,3}$ The mortality is attributed to delayed diagnosis, the barriers to HIV diagnosis and late initiation and presentation of HIV positive patients for HIV treatment. ${ }^{4,5}$ In addition, the delay in diagnosis and initiation of ART treatment increases the risk of reduced CD4 counts, increased risk of comorbidities, HIV-related anaemia that increases the risk of advanced morbidity and mortality. ${ }^{6}$ Evidence shows that early HIV treatment initiation is reliant on early HIV diagnosis, prompt linkage to HIV care as well as retention in care. The Uganda Ministry of Health (MOH) adopted the HIV self-testing (HIVST) guidelines as an effort towards UNAID's 95-95-95 target by 2030. HIV oral self-test provides an added advantage to the conventional testing approaches because the HIVST can be performed through unassisted approaches in communities without monitoring of a health-care worker. The goal was to identify $95 \%$ of people living with HIV within every age and sex strata to supplement the existing HIV testing and counselling approaches. ${ }^{7}$ However, despite the 
progress to have all PLHIV sustained on ART (linkage to ART), the country was still below the $90 \%$ target by 2020 at $85 \%$. This low rate of linkage to HIV care has been attributed to several factors including fear of being seen at the clinic, fear of disclosing, not feeling sick, transportation costs, distance to the clinic, unkind health workers, drug stock-outs, and persistent HIV stigma. ${ }^{8-10}$ Since the rollout of HIVST in Uganda, there has been an increasing acceptability and uptake of HIVST among the population especially the key population (19-22). According to data from the District Health Information Software 2 (DHIS2), approximately 169,031 individuals were tested for HIV using the oral HIVST approach in 2020, among which 53\% $(90,076 / 169,031)$ utilized directly assisted HIVST method. The rate of HIV positivity among those who utilized the HIVST was about 3\% $(4873 / 169,031)$ in 2020 according to DHIS2 (2020). In addition, data from the DHIS 2 show that only $60 \%$ of individuals who tested positive on oral HIVST were linked to a confirmatory test using the HIV testing national algorithm. We think that approximately this is the similar number that were further linked to HIV care after having the HIV confirmatory test, indicating low linkage to HIV care compared to the UNAIDS target of 2020, and 2035.

Data from the DHIS2 (2020) resonates well with other studies done in Uganda $(23,24)$ and sub-Saharan Africa $(25-$ 27) have shown low linkage to HIV care. Several factors are thought to limit linkage to HIV care after testing positive with oral HIVST. These include: the inconvenience of accessing the clinic (travel, wait, expense, opportunity costs), fear or avoidance of a needle stick needed for confirmatory testing, or privacy concerns among key population groups. Despite the available evidence of low linkage to care, the reasons for this low linkage after testing positive with oral HIVST are not well documented. Therefore, in this study, we sought to determine the factors associated with linkage to HIV care among adults with positive oral HIV self-testing results. We believe that understanding this knowledge gap is critical to the success of the national HIV response in Uganda.

\section{Methods}

\section{Study Design}

This was a cross-sectional study, with quantitative data collected through structured interviews and a review of medical records captured between January 2019 and May 2020. Data collection was carried out from July to August 2020.

\section{Study Setting}

The study was conducted at Entebbe regional referral hospital and Nabweru Health Centre III.

Entebbe Regional Referral Hospital is located in the town of Entebbe, Wakiso district, in the central region of Uganda. Nabweru Health Centre III is located in Nansana Municipal Council, Wakiso district. These health facilities are part of the community distribution centres for HIV oral self-test kits under MOH. The HIVST kit distribution exercise is done through community outreaches where OraQuick HIV oral self-testing kits are distributed to adults. ${ }^{7}$

\section{Sampling Procedure}

The study included all adults (aged 18 years) receiving HIVST kits at Entebbe regional referral hospital and Nabweru Health centre III under the MOH distribution exercise as recorded in the HIV self-testing distribution log. Participants with reactive HIV oral self-test results were invited through a phone call to participate in the study. Participants who were linked to HIV care were required to present an ART card which indicated they were registered for ART treatment. Participants were consecutively sampled until the sample size was achieved.

\section{Eligibility Criteria \\ Inclusion Criteria}

Participants who tested HIV positive on oral self-test kits, presenting an ART card among those who linked to care and consented to participate in the study were included.

\section{Exclusion Criteria}

Those who had started HIV treatment before January 2019 were excluded from the study. 


\section{Data Collection, Variables, and Measurements}

Phone numbers, sex, key population, type of HIV self-testing, test kit distribution purpose, HIVST results were extracted from the HIV self-testing distribution log for participants who were positive on HIV oral self-test using a data abstraction form designed for this study as a screening tool. A structured questionnaire with closed-ended questions on patient demographics, socio-economic characteristics and health-related factors was used to collect data from eligible participants (Supplementary material). The demographic and socioeconomic factors included age, sex, religion, education level, income status, employment status, marital status, alcohol consumption, parenting and media exposure. The health-related factors included key population groups, location of HIVST kit distribution point, type of HIV oral self-testing, test kit distribution purpose, time-taken to reach the health facility, quality of health care and means of transport to the health facility, denial of HIVST results, stigma, HIV status disclosure, perceived state of health, knowledge of ART side effects, the likelihood of experiencing side effects, living with HIV positive person in the same household and HIV counselling.

The study tools were pre-tested at a health facility in Kampala. Data was collected by qualified staff with experience in data collection and fluent in the local language of the study setting. The study research assistants were trained on the study procedures and ethical conduct of research before data collection commenced.

The outcome variable was linkage to HIV care, and this was defined as whether the individual who tested positive on HIV oral self-test got an HIV confirmatory test was either registered or not registered for ART treatment as observed using the ART card.

\section{Sample Size}

The formula for sample size calculation for a cross-sectional study was used to estimate the number of participants to be sampled using Epi info ${ }^{\circledR}$ software. We assumed a two-sided alpha value of 0.05 , power at $90 \%$, the ratio of participants with positive HIV oral self-test linked to HIV care to those positive with HIV self-test not linked to HIV care as 1:2 and a minimum.

Prevalence rate ratio of 0.3 . Considering the prevalence of linkage to HIV care among adults testing positive with HIV oral self-testing to be $50 \%$, and using the Kelsey formulae, the total sample size was estimated to be 143 .

\section{Statistical Analysis}

Data were analysed using STATA version 14.0. Frequencies and their corresponding percentages were used for categorical variables and mean with standard deviation were used for continuous variables that were normally distributed. Univariate analysis was done using the Mann-Whitney $U$-test for continuous variables and the chi-square test or Fisher's exact for categorical variables. The dependent variable was modelled as a binary outcome. Bivariate and multivariable analysis was done using robust modified Poisson regression using prevalence rate ratios as a measure of association. Robust modified Poisson logistic regression was used because the outcome variable is a common event $(>10 \%)$, thus using the odds ratio with ordinary logistic regression would overestimate the risk ratio. In addition, Poisson regression with robust variance regression provide correct estimates and are a better alternative for the analysis of cross-sectional studies with binary common outcomes. ${ }^{11}$ All variables with $\mathrm{p}<0.02$ at bivariate analysis were included in a correlation model to remain with a correlation coefficient greater than +0.4 and less than $<-0.4$. Backward elimination was then used to build the final multivariable model, by eliminating variables with a p-value greater than 0.05 . Factors specified as important based on previous literature were included in the final model. A two-sided significance p-value of 0.05 and a $95 \%$ confidence interval were considered statistically significant for the analysis. Measures of association were reported as unadjusted prevalence rate ratio on bivariate analysis and adjusted prevalence rate ratio on multivariable analysis.

\section{Results}

\section{Characteristics of the Study Participants}

The study successfully reached out to $81 \%$ (196/243) of the patients through phone call invitations, and 59.3\% (144/196) agreed to participate in the study. Table 1 shows the sociodemographic characteristics of the study participants. Among the 144 participants, $69 \%(100 / 144)$ had successfully been linked to HIV care. The mean age of the participants was 28 \pm 8 years, with the majority of the participants in the age group of $18-25$ years. The majority $(72 \%)$ of the participants 
were female. Considering the key population, 44\% (64/144) of the participants were from the general population, $43 \%$ (63/144) were female sex workers, $6 \%(9 / 144)$ were men who have sex with men, and 5\% (8/144) were men through prevention of mother to child transmission (PMTCT) program. More than half (56\%) of the participants had attained a secondary or vocational level of education, and up to $88 \%$ (127/144) of the participants were able to read. Considering income status, over half (54\%) earned less than USD 27.0 per month. The mean time to reach a health facility was $41 \pm 22$ minutes, with the majority (51\%) of the participants using a motorcycle and taxis as a means of transport to the health facility.

Table 2 shows the health-related characteristics of the study participants. The majority (78\%) of the study participants reported being in good health, 18\% (16/144) reported being in poor health, and 4\% (5/144) reported being in excellent health. The majority (91\%) of the participants received HIVST from the community distribution centres while the rest received them from the health facility. Seventy-eight (54\%) of the participants reported using unassisted HIVST, with more than half (51\%) of these linked to HIV care. The majority (71\%) of the participants reported having disclosed their HIV status to a family member or a friend, while $62(43 \%)$ participants reported having been very ready to start ART.

\section{Factors Associated with Linkage to HIV Care}

Results in Table 3 show the factors associated with linkage to HIV care. Linkage to HIV care was 39\% and $46 \%$ more likely among age groups of $31-35$ years $(\mathrm{APRR}=1.39,95 \% \mathrm{CI}=1.061-84, \mathrm{P}<0.05)$ and that of $41-60$ years $(\mathrm{APRR}=$ $1.46,95 \% \mathrm{CI}=1.06-2.00, \mathrm{P}<0.05)$, respectively. Table 3 shows that participants who used directly assisted HIVST were $93 \%$ more likely to be linked to care compared to those who utilized unassisted HIVST (PRR $=1.93,95 \% \mathrm{CI}=$ $1.522-44, \mathrm{P}<0.001)$. Participants who do not consume alcohol were $26 \%$ more likely compared to those who do not consume alcohol $(\mathrm{APRR}=1.26,95 \% \mathrm{CI}=1.04-1.53, \mathrm{P}<0.05)$. In addition, Table 3 shows that those with sexual partner support $(\mathrm{PRR}=1.46,95 \% \mathrm{CI}=1.30-1.65, \mathrm{P}<0.001)$, participants who spend less than $61-120$ minutes to reach the health facility $(\mathrm{PRR}=2.0,95 \% \mathrm{CI}=1.34-2.99, \mathrm{P}<0.01)$, those who can disclose their HIV status to their sexual partners $(\mathrm{PRR}=1.32,95 \% \mathrm{CI}=1.03-1.69, \mathrm{P}<0.05)$ and participants' readiness to start $\mathrm{ART}(\mathrm{PRR}=1.85,95 \% \mathrm{CI}=$ $1.25-2.74, \mathrm{P}<0.01$ ) were $46 \%, 2$ times, $32 \%$, and $85 \%$ more likely to be linked to care compared with their counterparts. Participants who were female were $18 \%$ less likely to be linked to care compared to males (APRR $=0.82,95 \% \mathrm{CI}=$ $0.68-0.99, \mathrm{P}<0.05)$. Also, single participants/never married ( $\mathrm{PRR}=0.64,95 \% \mathrm{CI}=0.53-0.78, \mathrm{P}<0.001)$ or separated/ divorced $(\mathrm{PRR}=0.59,95 \% \mathrm{CI}=0.41-0.86, \mathrm{P}<0.01$ ) were $36 \%$ and $41 \%$ less likely to be linked to care compared to the married ones. Participants who fear unfair treatment after HIV status disclosure were $33 \%$ less likely to be linked to care compared to those who did not fear unfair treatment following HIV disclosure (APRR $=0.67,95 \% \mathrm{CI}=0.46-0.97$, $\mathrm{P}<0.05)$.

Furthermore, participants with fear of likely getting ART side effects (APRR $=0.71,95 \% \mathrm{CI}=0.54-0.95, \mathrm{P}<0.05$ ) were $29 \%$ less likely to be linked to HIV care compared to those without any fear.

\section{Discussion}

The results from this study show that linkage to HIV care was positively associated with age, the type of HIV selftesting, HIV status disclosure, the readiness to start ART, non-alcohol consumption, having a supportive sexual partner and was negatively associated with marital status, sex, stigma associated factors and fear of ART side effects. These findings suggest that several factors are limiting linkage to HIV care after self-testing HIV positive. This would increase the risk of advanced morbidity due to delayed ART initiation and subsequent burden to the public healthcare system.

This study showed that linkage to HIV care among adults with positive HIV oral self-testing results was $69 \%$, which is below the UNAIDS target of $90 \%$ by 2020 and $95 \%$ by 2030 for individuals who know their HIV status started and sustained on ART treatment. This proportion is higher than that of a study done in 20 health facilities in Uganda that showed linkage of HIV care to be 53\%. ${ }^{12}$ This may be attributed to the lower sample size in this study.

The study demonstrated that age has a positive association with linkage to HIV care with participants within the age of 31-35 years and 41-60 years more 39\% and 46\% more likely to be linked to HIV care compared to other age brackets. These results are similar to those of studies done in Uganda ${ }^{13}$ and South Africa ${ }^{14}$ that showed that PLHIV in the age 
Table I Socio-Demographic Characteristics of the Study Participants

\begin{tabular}{|c|c|c|c|c|}
\hline Characteristics and their Categories & $\begin{array}{l}\text { All Participants n= |44 } \\
\text { n (\%) or Mean (SD) }\end{array}$ & $\begin{array}{l}\text { Linked to ART } n=100 \\
n(\%) \text { or Mean (SD) }\end{array}$ & $\begin{array}{c}\text { Not-Linked to ART } n=44 \\
n(\%) \text { or Mean (SD) }\end{array}$ & p-value \\
\hline Age (years) & & & & 0.021 \\
\hline $18-25$ & $64(45)$ & $39(61)$ & $25(39)$ & \\
\hline $26-30$ & $34(24)$ & $23(68)$ & $11(32)$ & \\
\hline $31-35$ & $22(15)$ & $16(73)$ & $6(27)$ & \\
\hline $36-40$ & $10(7)$ & $9(90)$ & $I(10)$ & \\
\hline $4 I-60$ & $13(9)$ & $12(92)$ & $\mathrm{I}(8)$ & \\
\hline Sex & & & & 0.088 \\
\hline Female & $104(72)$ & $68(68)$ & $36(82)$ & \\
\hline Male & $40(28)$ & $32(32)$ & $8(18)$ & \\
\hline Key population groups & & & & $<0.001$ \\
\hline FSW & $63(43)$ & $27(43)$ & $36(57)$ & \\
\hline$G P$ & $64(44)$ & $63(98) 2$ & I (2) & \\
\hline MSM & $9(6)$ & $2(22)$ & $7(78)$ & \\
\hline MTA & $8(5)$ & $8(100)$ & 0 & \\
\hline Education level & & & & 0.207 \\
\hline No formal education & II (8) & $5(45)$ & $6(55)$ & \\
\hline Primary & $48(33)$ & $35(73)$ & $13(27)$ & \\
\hline Secondary/vocational & $81(56)$ & $58(72)$ & $23(28)$ & \\
\hline Higher education & $4(3)$ & $2(50)$ & $2(50)$ & \\
\hline Able to read & & & & 0.311 \\
\hline Yes & $127(88)$ & $90(8 \mathrm{I})$ & $37(84)$ & \\
\hline No & $17(12)$ & $10(10)$ & $7(16)$ & \\
\hline Religion & & & & 0.934 \\
\hline Anglican & $29(20)$ & $20(69)$ & $9(31)$ & \\
\hline Catholic & $52(36)$ & $36(69)$ & $16(31)$ & \\
\hline Seventh-day & $3(2)$ & $3(100)$ & 0 & \\
\hline Saved/Pentecostal & $16(12)$ & $12(7 \mid)$ & $5(29)$ & \\
\hline Moslem & $42(29)$ & $28(67)$ & $14(33)$ & \\
\hline Marital status & & & & $<0.001$ \\
\hline Married & $39(27)$ & $37(95)$ & $2(5)$ & \\
\hline Single (never married) & $77(54)$ & $47(6 \mathrm{I})$ & $30(39)$ & \\
\hline Separated/divorced & $23(16)$ & $13(57)$ & $10(43)$ & \\
\hline Widowed & $5(3)$ & $3(60)$ & $2(40)$ & \\
\hline Have children & & & & 0.209 \\
\hline Yes & $105(73)$ & $76(72)$ & $29(28)$ & \\
\hline No & $39(27)$ & $24(62)$ & $15(38)$ & \\
\hline Income status (UGX) & & & & 0.180 \\
\hline$<50,000$ & $39(27)$ & $31(79)$ & $8(2 I)$ & \\
\hline $50-100,000$ & $38(26)$ & $23(61)$ & $15(39)$ & \\
\hline $100-350,000$ & $51(36)$ & $37(73)$ & $14(27)$ & \\
\hline $350-500,000$ & $10(7)$ & $6(60)$ & $4(40)$ & \\
\hline$>500,000 /=$ & $5(4)$ & $2(40)$ & $3(60)$ & \\
\hline Consume alcohol & & & & 0.053 \\
\hline Yes & $55(38)$ & $33(60)$ & $22(40)$ & \\
\hline No & $89(62)$ & $67(75)$ & $22(25)$ & \\
\hline
\end{tabular}

(Continued) 
Table I (Continued).

\begin{tabular}{|c|c|c|c|c|}
\hline Characteristics and their Categories & $\begin{array}{l}\text { All Participants n= I44 } \\
n(\%) \text { or Mean (SD) }\end{array}$ & $\begin{array}{l}\text { Linked to ART } n=100 \\
n(\%) \text { or Mean (SD) }\end{array}$ & $\begin{array}{c}\text { Not-Linked to ART n=44 } \\
n(\%) \text { or Mean (SD) }\end{array}$ & p-value \\
\hline Time on takes to hospital (minutes) & & & & $<0.001$ \\
\hline $\mathrm{I}-20$ & $24(17)$ & $12(50)$ & $12(50)$ & \\
\hline $21-40$ & $63(44)$ & $40(63)$ & $23(37)$ & \\
\hline $4 I-60$ & $49(35)$ & $40(82)$ & $9(18)$ & \\
\hline Above 60 & $6(4)$ & $6(100)$ & 0 & \\
\hline Means of transport & & & & 0.024 \\
\hline Walking & $35(24)$ & $18(51)$ & $17(49)$ & \\
\hline Boda-Boda, & $73(5 I)$ & $52(7 I)$ & $21(29)$ & \\
\hline Taxi (Matatu) & $35(24)$ & $29(83)$ & $6(17)$ & \\
\hline Public bus & $I(I)$ & $I(100)$ & 0 & \\
\hline Cost of transport (UGX) & & & & 0.019 \\
\hline$<5000$ & $97(67)$ & $61(63)$ & $36(37)$ & \\
\hline 6000 to 15,000 & $38(26)$ & $30(79)$ & $8(21)$ & \\
\hline More than 15,000 & $9(6)$ & $9(100)$ & 0 & \\
\hline Quality of health care received & & & & $<0.001$ \\
\hline Very good & $52(36)$ & $49(94)$ & $3(6)$ & \\
\hline Good & $82(57)$ & $47(57)$ & $35(43)$ & \\
\hline Not good & $9(7)$ & $4(44)$ & $5(56)$ & \\
\hline
\end{tabular}

Note: The bold font was used to show statistically significant $p$-values $(p<0.05)$.

Abbreviations: FSW, female sex worker; GP, general population; MSM, men who have sex with men; MTA, men through Antenatal care; UGX, Ugandan Shilling; ART, antiretroviral therapy.

bracket of 30-39 years were more likely to be linked to HIV care compared to other age groups. A likely explanation for this association may be that individuals in these age groups have a sense of responsibility for their lives and families, as well as being familiar with the health-care system.

The study showed that females were $18 \%$ less likely to be linked to HIV care compared with males. These results are surprising in that several studies in Uganda ${ }^{15,16}$ and elsewhere ${ }^{16,17}$ have shown the contrary, with one study on HIVST having shown that testing HIV positive among men did not increase the likelihood of linkage to HIV care in Uganda. ${ }^{18}$ Our results could not be explained by this study; however, this could be attributed to stigma and discrimination most commonly faced by women while seeking HIV health care. ${ }^{19}$

Furthermore, social norms suggest that women require to seek permission from men to seek health care ${ }^{20}$ which may limit their freedom to linkage to HIV care.

The readiness to start ART treatment has been shown to enable linkage to HIV care and ART treatment uptake in Uganda. ${ }^{21}$ Adding to this evidence, the study results show that participants who were ready to start ART treatment were $89 \%$ more likely to be linked to HIV care compared to those who were not ready. However, study findings also suggest that participants with fears regarding ART side effects are 0.58 times less likely to be linked to care. These study findings are similar to evidence from elsewhere that show having thoughts of drug side-effects is associated with poor uptake of treatment. $^{22,23}$ These concerns continue to impact individuals' decisions, especially if accompanied with wrong information about the side effects HIV positive people get when on ART.

Sexually active participants, who self-identified themselves as either single or separated (divorced) were $36 \%$ and $41 \%$ less likely to be linked to HIV care compared to married participants. The findings align with evidence from another study in South Africa among newly diagnosed patients. ${ }^{22}$ There is thus increasing evidence of the importance of targeted HIV counselling among these HIV positive individuals as a form of HIV control and prevention to increase awareness of the benefits of early initiation on ART. 
Table 2 Health-Related Characteristics of the Study Participants

\begin{tabular}{|c|c|c|c|c|}
\hline Characteristics and their Categories & $\begin{array}{l}\text { All Participants } n=144 \\
n(\%)\end{array}$ & $\begin{array}{c}\text { Linked to ART } n=100 \\
n(\%)\end{array}$ & $\begin{array}{c}\text { Not-Linked to ART } n=44 \\
n(\%)\end{array}$ & p-value \\
\hline Health status & & & & 0.873 \\
\hline Poor health & $26(18)$ & $18(69)$ & $8(31)$ & \\
\hline Good health & $113(78)$ & $79(70)$ & $34(30)$ & \\
\hline Excellent health & $5(4)$ & $3(60)$ & $2(40)$ & \\
\hline HIVST kits distribution point & & & & 0.986 \\
\hline Community & $|3|(9 \mid)$ & $91(69)$ & $40(31)$ & \\
\hline Health facility & $13(9)$ & $9(69)$ & $4(3 I)$ & \\
\hline Type of HIVST & & & & $<0.001$ \\
\hline Directly assisted & $66(46)$ & $62(94)$ & $4(6)$ & \\
\hline Unassisted & $78(54)$ & $38(49)$ & $40(5 \mathrm{I})$ & \\
\hline Denial of HIVST results & & & & 0.490 \\
\hline Yes & $90(65)$ & $63(70)$ & $27(30)$ & \\
\hline No & $49(35)$ & $37(76)$ & $12(24)$ & \\
\hline Knowledge of anyone taking ART at home & & & & 0.196 \\
\hline Yes & $61(42)$ & $44(72)$ & $17(28)$ & \\
\hline No & $72(50)$ & $5 I(7 \mid)$ & $21(29)$ & \\
\hline I do not know & II (8) & $5(45)$ & $6(55)$ & \\
\hline Know of ART side effects & & & & 0.020 \\
\hline Yes & $78(54)$ & $59(76)$ & $19(24)$ & \\
\hline No & $49(34)$ & $34(69)$ & $15(3 \mid)$ & \\
\hline I do not know & $17(12)$ & $7(4 I)$ & $10(59)$ & \\
\hline Likely to get ART side effects & & & & $<0.001$ \\
\hline Not likely & $55(38)$ & $52(95)$ & $3(5)$ & \\
\hline Somewhat likely & $22(15)$ & $15(68)$ & $7(32)$ & \\
\hline Very likely & $34(24)$ & $23(68)$ & $11(32)$ & \\
\hline I do not know & $33(23)$ & $10(30)$ & $23(70)$ & \\
\hline Received HIV counselling & & & & $<0.001$ \\
\hline Yes & I35 (94) & $99(73)$ & $36(27)$ & \\
\hline No & $9(6)$ & I (II) & $8(89)$ & \\
\hline Disclosed to the sexual partner & & & & 0.011 \\
\hline Yes & $84(59)$ & $65(77)$ & $19(23)$ & \\
\hline No & $58(40)$ & $34(59)$ & $24(4 I)$ & \\
\hline I do not want to & $\mathrm{I}(\mathrm{I})$ & 0 & I (100) & \\
\hline Disclosed to family/friend & & & & 0.001 \\
\hline Yes & $102(7 \mathrm{I})$ & $75(74)$ & $27(26)$ & \\
\hline No & $36(25)$ & $25(69)$ & II (3I) & \\
\hline I do not want to & $6(4)$ & 0 & $6(100)$ & \\
\hline $\begin{array}{l}\text { Thought of being treated unfairly if disclosed to partner / } \\
\text { family }\end{array}$ & & & & $<0.001$ \\
\hline Not likely & $68(47)$ & $57(84)$ & $11(16)$ & \\
\hline Somehow likely & $30(2 I)$ & $23(77)$ & $7(23)$ & \\
\hline Very likely & $30(21)$ & $15(50)$ & $15(50)$ & \\
\hline I do not know & $16(11)$ & $5(3 I)$ & II (69) & \\
\hline Ready to start ART & & & & $<0.001$ \\
\hline Very ready & $62(43)$ & $50(8 I)$ & $12(19)$ & \\
\hline Ready & $42(29)$ & $33(79)$ & $9(2 \mathrm{I})$ & \\
\hline Not ready & $40(28)$ & $17(42)$ & $23(58)$ & \\
\hline
\end{tabular}

Note: The bold font was used to show statistically significant $p$-values $(p<0.05)$.

Abbreviations: STD, sexually transmitted diseases; ART, antiretroviral therapy. 
Table 3 Factors Associated with Linkage to HIV Care at Bivariate and Multivariate Analysis

\begin{tabular}{|c|c|c|c|c|}
\hline Characteristics and Categories & $\begin{array}{l}\text { Unadjusted Prevalence } \\
\text { Rate-Ratio }(95 \% \mathrm{Cl})\end{array}$ & p-value & $\begin{array}{l}\text { Adjusted Prevalence } \\
\text { Rate-Ratio }(95 \% \mathrm{Cl})\end{array}$ & p-value \\
\hline \multicolumn{5}{|l|}{ Age (years) } \\
\hline$<25$ & 1.0 & & 1.0 & \\
\hline $26-30$ & I.II (0.82-I.5I) & 0.502 & I.I3 (0.89-I.45) & 0.333 \\
\hline $31-35$ & $1.19(0.86-1.65)$ & 0.284 & $1.39(1.06-1.84)$ & 0.019 \\
\hline $36-40$ & $1.48(1.11-1.97)$ & 0.008 & $1.36(0.96-1.93)$ & 0.079 \\
\hline $4 I-60$ & $1.52(1.18-1.95)$ & 0.001 & $1.46(1.06-2.00)$ & 0.022 \\
\hline \multicolumn{5}{|l|}{ Sex } \\
\hline Male & 1.0 & & 1.0 & \\
\hline Female & $0.82(0.66-1.01)$ & 0.059 & $0.82(0.68-0.99)$ & 0.044 \\
\hline \multicolumn{5}{|l|}{ Education level } \\
\hline No formal education & 1.0 & & & \\
\hline Primary & $1.6(0.82-3.14)$ & 0.168 & & \\
\hline Secondary/vocational & $1.58(0.8 \mathrm{I}-3.06)$ & 0.180 & & \\
\hline Higher education & I.I (0.34-3.57) & 0.874 & & \\
\hline \multicolumn{5}{|l|}{ Type of HIV self-testing } \\
\hline Unassisted HIVST & 1.0 & & & \\
\hline Directly assisted HIVST & $1.93(1.52-2.44)$ & $<0.001$ & & \\
\hline \multicolumn{5}{|l|}{ Marital status } \\
\hline Married & 1.0 & & & \\
\hline Single (never married) & $0.64(0.53-0.78)$ & $<0.001$ & & \\
\hline Separated/divorced & $0.59(0.4 I-0.86)$ & 0.006 & & \\
\hline Widowed & $0.63(0.3|-| .30)$ & 0.214 & & \\
\hline \multicolumn{5}{|l|}{ Have children } \\
\hline No & 1.0 & & & \\
\hline Yes & I.I8 (0.89-I.55) & 0.249 & & \\
\hline \multicolumn{5}{|l|}{ Work time } \\
\hline Throughout the year & 1.0 & & 1.0 & \\
\hline Seasonally & $1.67(1.34-2.06)$ & $<0.001$ & I.I (0.9-I.33) & 0.355 \\
\hline Once in a while & 1.31 (0.98-1.77) & 0.073 & $1.23(0.98-1.55)$ & 0.079 \\
\hline \multicolumn{5}{|l|}{ Income status (UGX) } \\
\hline$<50,000$ & 1.0 & & & \\
\hline $50,001-100,000$ & $0.76(0.56-1.03)$ & 0.078 & & \\
\hline $100,001-350,000$ & $0.91(0.72-1.15)$ & 0.442 & & \\
\hline $350-500,000$ & $0.75(0.44-1.29)$ & 0.301 & & \\
\hline$>500,000$ & $0.50(0.17-1.49)$ & 0.217 & & \\
\hline \multicolumn{5}{|l|}{ Drinking alcohol } \\
\hline Yes & 1.0 & & 1.0 & \\
\hline No & $1.25(0.98-1.6 I)$ & 0.072 & $1.26(1.04-1.53)$ & 0.019 \\
\hline \multicolumn{5}{|l|}{ Decision about health care } \\
\hline Myself & 1.0 & & & \\
\hline Partner & $1.46(1.30-1.65)$ & $<0.001$ & & \\
\hline Myself and my partner & $0.98(0.43-2.19)$ & 0.955 & & \\
\hline My parents/guardian & $1.13(0.82-1.55)$ & 0.466 & & \\
\hline
\end{tabular}

(Continued) 
Table 3 (Continued).

\begin{tabular}{|c|c|c|c|c|}
\hline Characteristics and Categories & $\begin{array}{c}\text { Unadjusted Prevalence } \\
\text { Rate-Ratio }(95 \% \mathrm{Cl})\end{array}$ & p-value & $\begin{array}{l}\text { Adjusted Prevalence } \\
\text { Rate-Ratio }(95 \% \mathrm{CI})\end{array}$ & p-value \\
\hline \multicolumn{5}{|l|}{ Travel time to a health facility } \\
\hline$<20$ minutes & 1.0 & & 1.0 & \\
\hline $21-40$ minutes & $1.27(0.82-1.98)$ & 0.291 & $1.28(0.88-1.87)$ & 0.202 \\
\hline $4 I-60$ minutes & $1.63(1.07-2.49)$ & 0.023 & $1.27(0.88-1.83)$ & 0.210 \\
\hline $61-120$ minutes & $2.0(1.34-2.99)$ & 0.001 & $\mathrm{I} .4 \mathrm{I}(0.98-2.04)$ & 0.065 \\
\hline \multicolumn{5}{|l|}{ Time to HIV confirmatory test } \\
\hline Same day & 1.0 & & & \\
\hline Within a week & $1.09(0.9|-| .31)$ & 0.369 & & \\
\hline$>a$ week & $0.88(0.69-1.12)$ & 0.302 & & \\
\hline Do not remember & $0.25(0.07-0.87)$ & 0.029 & & \\
\hline \multicolumn{5}{|l|}{ Received counselling } \\
\hline No & 1.0 & & 1.0 & \\
\hline Yes & $6.6(1.03-42.28)$ & 0.046 & $5.36(0.93-30.87)$ & 0.06 \\
\hline \multicolumn{5}{|l|}{ Disclosed to partner } \\
\hline No & 1.0 & & & \\
\hline Yes & $1.32(1.03-1.69)$ & 0.027 & & \\
\hline \multicolumn{5}{|c|}{ Thought of being treated unfairly if disclosed } \\
\hline Not likely & 1.0 & & 1.0 & \\
\hline Somehow likely & $0.91(0.73-1.14)$ & 0.435 & I.I (0.87-I.34) & 0.486 \\
\hline Very likely & $0.59(0.4 \mathrm{I}-0.86)$ & 0.007 & $0.67(0.46-0.97)$ & 0.032 \\
\hline I do not know & $0.37(0.18-0.78)$ & 0.009 & $0.51(0.28-0.92)$ & 0.025 \\
\hline \multicolumn{5}{|l|}{ Readiness to start ART } \\
\hline Not ready & 1.0 & & & \\
\hline Ready & $1.85(1.25-2.74)$ & 0.002 & & \\
\hline Very ready & $1.89(1.29-2.78)$ & 0.001 & & \\
\hline \multicolumn{5}{|l|}{ Knowledge of ART side effects } \\
\hline No & 1.0 & & & \\
\hline Yes & $1.09(0.87-1.37)$ & 0.453 & & \\
\hline I do not know & $0.59(0.32-1.08)$ & 0.088 & & \\
\hline \multicolumn{5}{|l|}{ Likely to get ART side effects } \\
\hline Not likely & 1.0 & & 1.0 & \\
\hline Somewhat likely & $0.72(0.54-0.97)$ & 0.029 & $0.71(0.54-0.95)$ & 0.018 \\
\hline Very likely & $0.72(0.56-0.91)$ & 0.007 & $0.80(0.64-1.01)$ & 0.056 \\
\hline I do not know & $0.32(0.19-0.54)$ & $<0.001$ & $0.42(0.26-0.68$ & $<0.001$ \\
\hline \multicolumn{5}{|l|}{ Means of transport } \\
\hline Walking & 1.0 & & 1.0 & \\
\hline Boda-boda & $1.39(0.97-1.97)$ & 0.072 & $1.33(0.95-1.84)$ & 0.093 \\
\hline Taxi (Matatu) & $1.61(1.13-2.30)$ & 0.009 & $1.31(0.94-1.84)$ & 0.114 \\
\hline \multicolumn{5}{|l|}{ Quality of health care services } \\
\hline Not good & 1.0 & & & \\
\hline Good & $\mathrm{I} .29(0.6 \mathrm{I}-2.75)$ & 0.510 & & \\
\hline Very good & $2.12(1.02-4.43)$ & 0.045 & & \\
\hline
\end{tabular}

Notes: I=reference category; the bold font was used to show statistically significant $p$-values $(p<0.05)$.

Abbreviations: $\mathrm{Cl}$, confidence interval; ART, antiretroviral therapy. 
The study had some strengths. The main strength was that the study was carried out among individuals who received services under the public health facility, thus providing a picture of the utilization of HIV self-testing services in the local setting. However, it also had some limitations. The results of this study cannot be generalised to the general population because of the smaller sample size and low response rate. The low response rate is attributed to the fact that the study was carried out in the middle of the COVID-19 pandemic. The study reviewed medical records for HIV oral self-testing to sample participants as well as answered the key outcome variable. There was a possibility of incomplete matching of study participants to medical records, this could have resulted in an error in the measurement of linkage to care, a measure of ART initiation. Extensive quality control checks to ensure completeness of data to reduce these limitations.

\section{Conclusion}

The study results show that linkage to HIV was more likely among participants with advanced age, those using directly assisted HIVST, disclosed their HIV status, received HIV counselling and ready to start ART and less likely among females, single or separated participants, those who consume alcohol, fear of unfair treatment after disclosure, and fear of getting ART side effects. HIV oral self-testing contributes to solutions in the HIV testing gap including the challenges facing efforts to scale up HIV testing mainly in the hard to reach areas and has a great role to play to get all PLHIV linked to HIV care. We recommend that local programs target the above factors affecting linkage to HIV care to greatly benefit from HIV self-testing services. More studies with a larger sample size are needed to add to these results by interrogating deeply the causes of low linkage among individuals utilizing this noble testing approach.

\section{Abbreviations}

APRR, adjusted prevalence rate ratio; ART, antiretroviral therapy; HIV/AIDS, human immunodeficiency virus/acquired immune deficiency syndrome; HIVST, HIV self-testing; HTC, HIV testing and counselling; HTS, HIV testing services; PRR, prevalence rate ratio; MOH, Ministry of Health Uganda; PLHIV, people Living with HIV; WHO, World Health Organisation; UNAIDS, Joint United Nations Programme on HIV/AIDS; UPHIA, Uganda Population-Based HIV Impact Assessment survey; MSM, men who have sex with men; FSW, female sex workers; PMTCT, prevention of mother to child transmission.

\section{Data Sharing Statement}

Materials and data analyzed during this study can be made available to all interested researchers upon reasonable request directed to the corresponding author, Mr Bbuye Mudarshiru on email; mudarshirubbuye@gmail.com.

\section{Ethical Approval and Consent}

Ethics approval for this study was obtained from the Makerere University School of Public Health Higher Degrees and the Ethics review committee. Administrative clearance was obtained from the Ministry of Health Uganda and the health facilities.

Written informed consent was obtained from the participants before attending interviews. Confidentiality of participants' information was ensured through coding unique identifiers for each participant. Interviews were conducted in a private setting identified in consultation with the participants. All participants who had not been linked to HIV care were counselled by the health facility counsellors and encouraged to start HIV treatment. This study complied with the Helsinki declaration.

\section{Acknowledgments}

We thank the study participants for their time and for agreeing to participate in the study. We acknowledge the health facility staff who assisted in data collection and the health-facility in-charges of the different health facilities. We acknowledge the implementing partners at health facilities including Mildmay, Uganda Cares, and Serving Lives Under Marginalisation (SLUM)-Community-based organization, Nabweru Uganda. 


\section{Author Contributions}

All authors made substantial contributions to conception and design, acquisition of data, or analysis and interpretation of data; took part in drafting the article or revising it critically for important intellectual content; agreed to submit to the current journal; gave final approval of the version to be published; and agree to be accountable for all aspects of the work.

\section{Funding}

This research reported was supported by the Fogarty International Centre of the National Institutes of Health, US Department of State's Office of the US Global AIDS Coordinator and Health Diplomacy (S/GAC), and President's Emergency Plan for AIDS Relief (PEPFAR) under Award Number 1R25TW011213. The content is solely the responsibility of the authors and does not necessarily represent the official views of the National Institutes of Health.

\section{Disclosure}

The authors declare that they have no conflicts of interest for this work.

\section{References}

1. UNAIDS. Global HIV and AIDS statistics. Global information and education on HIV and AIDS; 2019.

2. Kranzer K, Govindasamy D, Ford N, et al. Quantifying and addressing losses along the continuum of care for people living with HIV infection in sub-Saharan Africa: a systematic review. J Int AIDS Soc. 2012;15(2):17383. doi:10.7448/IAS.15.2.17383

3. Torian LV, Wiewel EW. Continuity of HIV-related medical care, New York City, 2005- 2009: do patients who initiate care stay in care? AIDS Patient Care STDS. 2011;25(2):79-88. doi:10.1089/apc.2010.0151

4. Gunda DWNkandala I, Kilonzo SB, et al. Prevalence and risk factors of mortality among adult HIV patients initiating ART in rural setting of HIV care and treatment services in north western Tanzania: a retrospective cohort study. J Sex Transm Dis. 2017;2017. 10.1155/2017/7075601

5. Manosuthi W, Charoenpong L, Santiwarangkana C. A retrospective study of survival and risk factors for mortality among people living with HIV who received antiretroviral treatment in a resource-limited setting. AIDS Res Ther. 2021;18(1):1-10. doi:10.1186/s12981-021-00397-1

6. Kiragga AN, Mubiru F, Kambugu AD, et al. A decade of antiretroviral therapy in Uganda: what are the emerging causes of death? BMC Infect Dis. 2019;19(1):1-6. doi:10.1186/s12879-019-3724-x

7. Ministry of Health, U. Guidance for Rollout of HIV Self-Testing in the Country. Uganda: Government; 2018:4.

8. Kiene SM, Sileo K, Wanyenze RK, et al. Barriers to and acceptability of provider-initiated HIV testing and counselling and adopting HIV-prevention behaviours in rural Uganda: a qualitative study. J Health Psychol. 2015;20(2):173-187.

9. Bwambale FM, Ssali SN, Byaruhanga S, et al. Voluntary HIV counselling and testing among men in rural western Uganda: implications for HIV prevention. BMC Public Health. 2008;8(1):263. doi:10.1186/1471-2458-8-263

10. Geng EH, Bangsberg DR, Musinguzi N, et al. Understanding reasons for and outcomes of patients lost to follow-up in antiretroviral therapy programs in Africa through a sampling-based approach. J Acquir Immune Defic Syndr. 2010;53(3):405. doi:10.1097/QAI.0b013e3181b843f0

11. Barros AJ, Hirakata VN. Alternatives for logistic regression in cross-sectional studies: an empirical comparison of models that directly estimate the prevalence ratio. BMC Med Res Methodol. 2003;3(1):1-13. doi:10.1186/1471-2288-3-21

12. Boeke CE, Nabitaka V, Rowan A, et al. Assessing linkage to and retention in care among HIV patients in Uganda and identifying opportunities for health systems strengthening: a descriptive study. BMC Infect Dis. 2018;18(1):138. doi:10.1186/s12879-018-3042-8

13. Lubogo D, DdamuLira JB, Tweheyo R, et al. Factors associated with access to HIV care services in eastern Uganda: the Kumi home based HIV counseling and testing program experience. BMC Fam Pract. 2015;16(1):162. doi:10.1186/s12875-015-0379-6

14. Maughan-Brown B, Harrison A, Galárraga O, et al. Factors affecting linkage to HIV care and ART initiation following referral for ART by a mobile health clinic in South Africa: evidence from a multimethod study. J Behav Med. 201942;1-15.

15. Mills EJ, Bakanda C, Birungi J, et al. Male gender predicts mortality in a large cohort of patients receiving antiretroviral therapy in Uganda. $J$ Int AIDS Soc. 2011;14(1):52. doi:10.1186/1758-2652-14-52

16. Braitstein P, Boulle A, Nash D, et al. Gender and the use of antiretroviral treatment in resource-constrained settings: findings from a multicenter collaboration. J Womens Health. 2008;17(1):47-55. doi:10.1089/jwh.2007.0353

17. Cornell M, Myer L, Kaplan R, et al. The impact of gender and income on survival and retention in a South African antiretroviral therapy programme. Trop Med Int Health. 2009;14(7):722-731. doi:10.1111/j.1365-3156.2009.02290.x

18. Vrana-Diaz C, Malek A, Musoke W, et al. Increasing HIV self-testing and linkage to care for partners of women in antenatal care in Uganda. International Initiative for Impact Evaluation; 2019.

19. Sambisa W, Curtis S, Mishra V. AIDS stigma as an obstacle to uptake of HIV testing: evidence from a Zimbabwean national population-based survey. AIDS Care. 2010;22(2):170-186. doi:10.1080/09540120903038374

20. Gibbons JL, Luna SE. For men life is hard, for women life is harder: gender roles in Central America. In: Psychology of Gender Through the Lens of Culture. Springer; 2015:307325.

21. Amuron B, Namara G, Birungi J, et al. Mortality and loss-to-follow-up during the pre-treatment period in an antiretroviral therapy programme under normal health service conditions in Uganda. BMC Public Health. 2009;9(1):290. doi:10.1186/1471-2458-9-290

22. Katz IT, Essien T, Marinda ET, et al. Antiretroviral refusal among newly diagnosed HIV-infected adults in Soweto, South Africa.. AIDS. 2011;25 (17):2177.

23. Naik R, Doherty T, Jackson D, et al. Linkage to care following a home-based HIV counselling and testing intervention in rural South Africa. J Int AIDS Soc. 2015;18(1):19843. doi:10.7448/IAS.18.1.19843 


\section{Publish your work in this journal}

HIV/AIDS - Research and Palliative Care is an international, peer-reviewed open-access journal focusing on advances in research in HIV, its clinical progression and management options including antiviral treatment, palliative care and public healthcare policies to control viral spread. The manuscript management system is completely online and includes a very quick and fair peer-review system, which is all easy to use. Visit http://www.dovepress.com/testimonials.php to read real quotes from published authors.

Submit your manuscript here: https://www.dovepress.com/hivaids-research-and-palliative-care-journal 